\title{
Reduced Graphene Oxide Supported Antimony Species for High-Performance Supercapacitor Electrodes
}

\author{
Mateusz Ciszewski, ${ }^{1}$ Andrzej Mianowski, ${ }^{1}$ Ginter Nawrat, ${ }^{1}$ and Piotr Szatkowski ${ }^{2}$ \\ ${ }^{1}$ Department of Inorganic, Analytical Chemistry and Electrochemistry, Faculty of Chemistry, \\ Silesian University of Technology, Krzywoustego 6, 44-100 Gliwice, Poland \\ ${ }^{2}$ Department of Biomaterials, Faculty of Materials Science and Ceramics, AGH University of Science and Technology, \\ Mickiewicza 30, 30-059 Krakow, Poland \\ Correspondence should be addressed to Mateusz Ciszewski; mateusz.ciszewski@polsl.pl
}

Received 15 January 2014; Accepted 11 February 2014; Published 5 March 2014

Academic Editors: D. Pavlov and E. Vallès

Copyright (C) 2014 Mateusz Ciszewski et al. This is an open access article distributed under the Creative Commons Attribution License, which permits unrestricted use, distribution, and reproduction in any medium, provided the original work is properly cited.

\begin{abstract}
Antimony species was chemically anchored on graphene oxide using antimony (III) chloride precursor and then converted to the reduced graphene oxide-antimony species composite by a well-established polyol method. The resultant composite was successfully used as supercapacitor electrodes in a two-electrode symmetric system with aqueous electrolyte. The specific capacitance calculated from the galvanostatic charge/discharge curves obtained for this composite was $289 \mathrm{~F} / \mathrm{g}$. The enhanced capacitance results were confirmed by the electrochemical impedance spectroscopy and cyclic voltammetry. The high capacitance of the reduced graphene oxide-antimony species composite arises from the combination of double-layer charging and pseudocapacitance caused by the Faradaic reactions of the intercalated antimony species and residual surface-bonded functional groups.
\end{abstract}

\section{Introduction}

Antimony is widely used in semiconductors, antifriction alloys, small arms and tracer bullets, and cable sheathing and in large quantities as a flame retarding additive [1]. It has been widely used in the past to enhance the hardness and the mechanical stability of lead alloys in batteries [2]. However, its usage was gradually limited because of toxicity, mostly of the trivalent species. In the lead batteries, antimony is generally known to be able to pass on a negative electrode through corrosion of current leads and decrease in the battery service life [3]. The detailed description of antimony reactions in lead batteries was given by Pavlov et al. [4], who suggested that the influence of the antimony on the lead battery work depends on antimony species used in battery preparation. In case of the lead electrodes immersed in the antimony solution, formation of $\mathrm{SbOSO}_{4}{ }^{-}$ions is observed that passivates the lead and decreases the capacitance. While for $\mathrm{Pb}-\mathrm{Sb}$ alloys in sulfuric acid solution formation of antimony complexes of the type $\mathrm{Sb}_{3} \mathrm{O}_{9}{ }^{3-}$ is observed that have a beneficial effect on the capacitance of electrodes. It is well known that antimony corrodes easily but results [5] suggest that the antimonycontaining corrosion layer discharges with difficulty, and thus the active material discharges more readily than the corrosion layer and a passivation layer does not form at the grid/active material interface. So it appears that addition of antimony to the active material of electrode effectively retards capacitance loss. These opinions seem to be true because antimony has been thoroughly examined as an additive in newer energy sources, that is, lithium-ion batteries, liquid metal batteries, and fuel cells.

In the lithium-ion batteries, antimony is thought to play two roles. First, it acts as a spacer to prevent large volume changing of electrode during charging/discharging cycles; second, it can accommodate about 3 lithium atoms and give an additional capacitance. Problem of anode pulverization during electrode working was examined mainly by Besenhard $[6,7]$ who suggested that improvement of cycling performance of the lithium-ion batteries can be achieved by replacing large metallic particles with smaller microand nanoscale multiphase. Billaud [8-10] studied methods of antimony-based graphite composites preparation by 
reduction of antimony (V) chloride with sodium hydride and alloying antimony with alkali metals. Except for antimonygraphite composites, there have been proposed many other combinations of antimony with metals and metal oxides [11, 12]. In tin oxide, additional atoms like antimony or indium may increase the electrical conductivity, mechanical stability, and the free electron concentration [13-15].

These researches indicate that antimony chemistry may play a crucial role in the new energy storage systems. As far as we know, application of graphene oxide-antimony species composites as a supercapacitor electrode was never reported before, though we have found some preliminary trials to synthesize peroxoantimonates on graphene oxide [16], simulate antimony (V) chloride intercalations into graphene sheets [17], and remove of antimony (III) from aqueous solution using graphene [18]. Electrochemical supercapacitors are promising energy storage systems due to low cost, long cycle life, and high power density that may be applied in many areas: video recorders, back-up memories, traffic warning signals, roadway display devices, and as the short time energy storage devices in electric vehicles and hybrid electric vehicles. Their high specific power can be used in engine starting and acceleration, loads lifting, and keeping the electric trains moving. Electrochemical supercapacitors, briefly, store electric energy in an electrochemical doublelayer, so-called Helmholtz layer, forming the solid electrolyte interface. As their capacitance is proportional to the surface area of the electrode material, highly porous, chemically and electrochemically inert carbons are considered as good candidates for supercapacitor matrices. Activated carbon that can be easily prepared from the various natural or synthetic precursors and can possess well-defined pore structure is still the main supercapacitors material because of very high surface area, low price, and light weight [19]. This situation may change using graphene, the parent of all graphitic forms, which emerges as a material of great interest due to its remarkable physical, chemical, and electrical properties.

It has high theoretical surface area up to $2630 \mathrm{~m}^{2} / \mathrm{g}$, Young's modulus as high as $1 \mathrm{TPa}$, and thermal conductivity of $5000 \mathrm{~W} /(\mathrm{mK})[20,21]$, which are beneficial for the capacitance performance. The prominent feature of graphene and graphene oxide is that they can form composites easily. In this case, naturally occurring electric double-layer effect can be enhanced by pseudocapacitance. Metals and metal oxides are most often suggested as graphene and graphene oxide additives that can be used in supercapacitor electrodes because of additional redox reactions that improve capacitance. Scientific interest is mainly focused on transition metals and tin composites with graphene oxide or reduced graphene oxide [22-24]. As antimony exhibited the advantageous effects in the lead acid batteries and lithium-ion batteries, it has been tried to embed antimony species into graphene oxide and examine this composite as the electrode for supercapacitor.

\section{Experimental}

2.1. Preparation of Antimony Composites. Graphite oxide (GO) was synthesized by a modified Staudenmaier method
[25] from the synthetic graphite (SGL Company). The polyol method [26] was used to prepare reduced graphene oxideantimony oxide hydroxide composite. Briefly, $300 \mathrm{mg}$ GO was ultrasonicated in 1:3 deionized water: ethylene glycol (Chempur) solution for $1 \mathrm{~h}$, resulting in graphene oxide suspension. Then, $0.337 \mathrm{~g} \mathrm{SbCl}_{3}$ (Acros) was added, $\mathrm{pH}$ was adjusted above 11 by $1 \mathrm{M} \mathrm{NaOH}$, and solution was magnetically mixed for $3 \mathrm{~h}$ at $600 \mathrm{rpm}$. Mixture was refluxed at $120^{\circ} \mathrm{C}$ for $3 \mathrm{~h}$ to reduce graphene oxide. Product was diluted with demineralized water, vacuum-filtrated on a fritted-glass funnel using filter paper with narrow pores (Munktel, Grade 390), and washed with water until neutral $\mathrm{pH}$. Solid product was dried at $110^{\circ} \mathrm{C}$ in an oven for $2 \mathrm{~h}$ and reduced graphene oxide-antimony species composite was labeled as RGOSb.

2.2. Characterization. Materials were characterized with powder X-ray diffraction (XRD, X'Pert Pro, Philips) with a step size $0.02^{\circ}$ and $\mathrm{Cu} \mathrm{K} \alpha$ radiation to evaluate reduction progress and identify antimony species. The crystallite height $\left(L_{C}\right)$ has been examined from XRD signals based on the Scherrer equation $\left(L_{C}=0.9 \lambda / B \cos \theta\right)$, where $\lambda$ is the wavelength of X-ray, $\theta$ is the Bragg's diffraction angle, and $B$ is a full width at half maximum (FWHM). The morphology of the products was characterized by scanning electron microscopy (SEM, Hitachi TM-3000). Raman spectroscopy was performed by using a Renishaw InVia with $514 \mathrm{~nm}$ laser excitation. The infrared spectra were measured on a Nicolet 6700 Fourier-transformed infrared spectrophotometer (FTIR) with attenuated total reflectance (ATR method).

2.3. Electrochemical Measurements. All electrochemical experiments were performed with Autolab PGSTAT 30 workstation using the two-electrode symmetric system. The working electrode and counter/reference electrode, composed of $15 \mathrm{mg}$ of active material and $2.5 \mathrm{mg}$ polytetrafluoroethylene (PTFE) binder (Sigma Aldrich, $35 \mu \mathrm{m}$ ), were pasted on two electrochemical nickel current collectors and separated with PTFE membrane (Whatman, $90 \mu \mathrm{m}$ thickness) soaked with $6 \mathrm{M} \mathrm{KOH}$. Weight of the electrodes was accurately determined by a high precision balance (Mettler Toledo AT 261 DeltaRange). The cells were tested by the cyclic voltammetry $(\mathrm{CV})$ at scan rates $5 \mathrm{mV} / \mathrm{s}, 20 \mathrm{mV} / \mathrm{s}$, and $500 \mathrm{mV} / \mathrm{s}$, galvanostatic charge/discharge (GD), and electrochemical impedance spectroscopy (EIS) in frequency range from $100 \mathrm{kHz}$ to $100 \mathrm{mHz}$. The impedance measurements were performed at an open circuit voltage with a $10 \mathrm{mV}$ voltage amplitude. The specific capacitance values were obtained from the galvanostatic charge/discharge curves using $C_{\mathrm{sp}}=i t /(m \mathrm{~d} U)$, where $i$ is the current, $t$ is the discharge time, $m$ is the mass of active material of the one electrode, and $\mathrm{d} U$ is the range of voltage. Capacitance was also obtained from the CV curves using the following formula:

$$
C=\frac{1}{\left(E_{2}-E_{1}\right) \nu} \int_{E_{1}}^{E_{2}} I(E) d E
$$

while specific capacitance using $C_{\mathrm{sp}}=2 \frac{\mathrm{C}}{\mathrm{m}}$, 


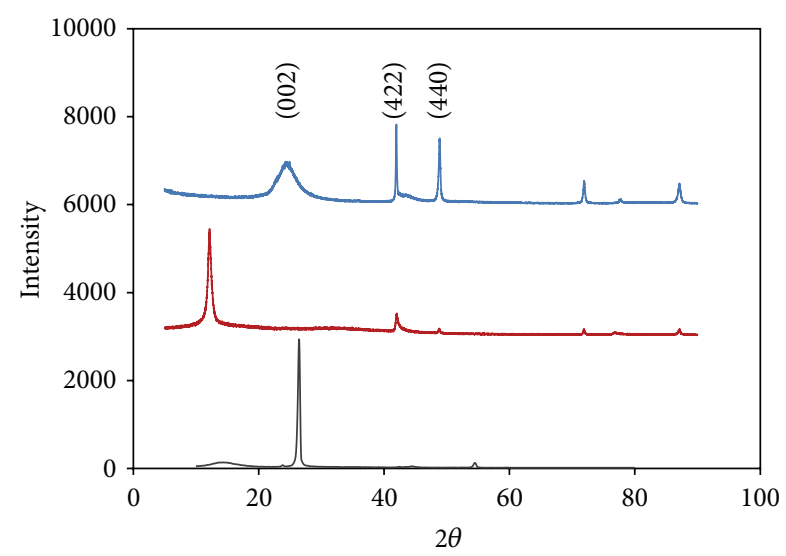

FIGURE 1: XRD patterns of graphite (gray), GO (red), and reduced graphene oxide-antimony species composite (blue).

where $E_{1}, E_{2}, \nu$, and $m$ are the initial potential, final potential, scan rate, and mass of the active material of one electrode, respectively. Using EIS method, capacitance was obtained from $C=2 \pi /\left(f Z^{\prime \prime}\right)$, where $f$ is the signal frequency and $Z^{\prime \prime}$ is the imaginary resistance.

\section{Results}

As mentioned previously, the polyol process using mixture of ethylene glycol and water was used to prepare reduced graphene oxide-antimony species composite. In comparison to the traditional reduction method using hydrazine or metal hydrides, the polyol process demonstrates an enhanced control of uniform metal dispersion and deposition as well as homogenous in situ generation of reducing species [27]. Antimony (III) chloride was used as a metal precursor. It is thought that this compound converts into antimony (III) oxide in basic $\mathrm{pH}$ [28]; however, at lower temperature more probably trivalent antimony hydroxide is formed [29]. Filella et al. [30] suggest that in the broad $\mathrm{pH}$ range from 2 up to 10 probably $\mathrm{Sb}(\mathrm{OH})_{3}$ or $\mathrm{SbO}(\mathrm{OH})$, called meta-antimonious acid $\left(\mathrm{HSbO}_{2}\right)$, is formed.

The exact formula of the antimony species after hydrolysis at high $\mathrm{pH}$ is precisely not known.

It was not possible to univocally identify the obtained XRD pattern. Except for typical and characteristic broad graphitic signal located near 25 degrees satisfying GO reduction, there were sharp signals belonging to antimony species recognized as the antimony oxide hydroxide of the form $\mathrm{Sb}_{3} \mathrm{O}_{6} \mathrm{OH}$ and antimony oxide hydrated $\mathrm{Sb}_{2} \mathrm{O}_{5} * 4 \mathrm{H}_{2} \mathrm{O}$. Figure 1 shows the powder XRD patterns of the parent graphite, GO, and RGOSb composite.

RGOSb composite was prepared in ethylene glycol that satisfied complete and uniform reduction of graphene oxide. Consequently, the broad signal in the graphitic region with the interlayer distance similar to that of parent graphite was observed. The XRD pattern of the RGOSb composite revealed also well-developed reflections of antimony species. This finding implies that the antimony salt truly cannot simply convert into antimony oxide but the oxide hydroxide or hydrated forms are preferred. Presence of antimony (III) and $(\mathrm{V})$ in the composite may suggest partial oxidation of antimony by GO.

SEM micrographs show the morphology of graphite, graphite oxide, and reduced graphene oxide-antimony species. Graphite intercalated by the oxygen-containing groups after oxidation has a rose-like, corrugated structure that can be observed in a Figure 2(b). As it was calculated from the XRD data, the crystallite height decreased significantly from $19.8 \mathrm{~nm}$ for graphite to $0.9 \mathrm{~nm}$ for GO. SEM micrograph of the RGOSb (Figure 2(c)) showed GO structure reduced in ethylene glycol with the antimony species intercalated between graphene layers. In RGOSb, an increase of the $L_{C}$ to $3.3 \mathrm{~nm}$ (calculated for reduced graphene oxide) caused by stacking of some of the graphene layers after reduction was observed.

Raman spectroscopy is a useful method to investigate hybridization of carbon atoms and defects and crystal disorder of graphene composites. Figure 3 presents Raman spectra recorded for the graphite, GO, and RGOSb. There are observed two vibration bands the $\mathrm{D}$ around $1,355 \mathrm{~cm}^{-1}$ and the $\mathrm{G}$ around $1,580 \mathrm{~cm}^{-1}$. The $\mathrm{D}$ band, corresponding to material disorder, is very small in highly ordered graphite structure, which is composed of equally distant, flat graphene layers consisting of $\mathrm{sp}^{2}$-hybridized carbon atoms; however, after oxidation, the $\mathrm{D}$ band intensity increases because of an increase in disorder caused by the oxygen-containing functional groups. In RGOSb, the D band intensity is higher than the $\mathrm{G}$ band because corrugated graphene layers of $\mathrm{GO}$ are partially separated by the reducing agent and smaller crystallites are formed. Additionally, the higher $\mathrm{D}$ band intensity in the RGOSb can be attributed to the formation of more defects in GO sheets during metal intercalation.

The $\mathrm{G}$ band that corresponds to $\mathrm{sp}^{2}$ carbons is broadened after oxidation and its intensity with respect to the $\mathrm{D}$ band diminishes due to change of the carbon atoms hybridization from $\mathrm{sp}^{2}$ to $\mathrm{sp}^{3}$. This effect is more marked in the RGOSb, where most of the residual $\mathrm{sp}^{2}$ carbon atoms are converted to $\mathrm{sp}^{3}$ and bonded to the intercalating molecules.

The intensity ratio $I_{\mathrm{D}} / I_{\mathrm{G}}$ is a convenient measure of disordered carbon that corresponds to amount of $\mathrm{sp}^{3}$ and $\mathrm{sp}^{2}$ carbon atoms. Graphite, possessing ordered and layered structure with high crystallite size, has the $I_{\mathrm{D}} / I_{\mathrm{G}}$ ratio of 0.34 and of GO 0.89 due to the increase in disorder of turbostratically aligned graphene layers and diminishing of randomly located crystallite size, while for RGOSb this ratio is 1.24 that is higher than for GO.

Qualitative analysis of composite and its precursor was performed using infrared spectroscopy. Figure 4 shows FTIR spectra recorded for GO and graphene oxide-antimony composite. GO spectrum shows a broad signal located at 3,700$2,800 \mathrm{~cm}^{-1}$ attributed to the stretching vibration in hydroxyl groups and water molecules, signal at $1,700 \mathrm{~cm}^{-1}$ belonging to the carboxylic groups, signal at $1,600 \mathrm{~cm}^{-1}$ belonging to $\mathrm{OH}$ groups, $1,350 \mathrm{~cm}^{-1}$ due to deformation vibration in C$\mathrm{OH}, 1,024 \mathrm{~cm}^{-1}$ represented by $\mathrm{C}-\mathrm{O}$ groups, and finally peak around $940 \mathrm{~cm}^{-1}$ from epoxy groups. 


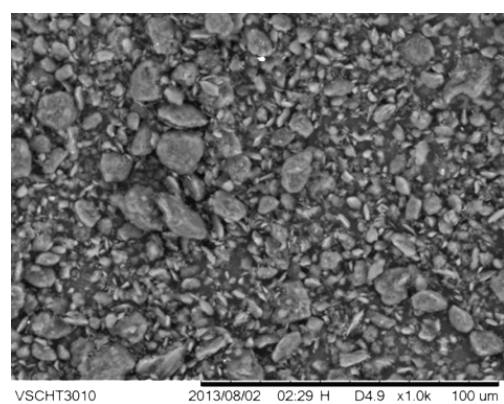

(a)

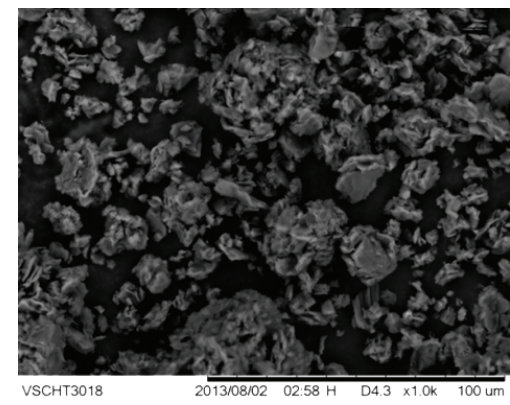

(b)

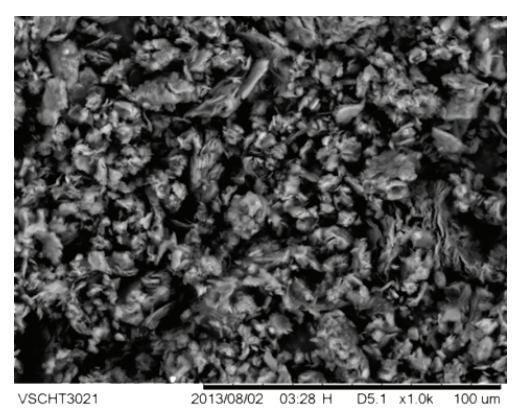

(c)

FIGURE 2: SEM images of graphite (a), GO (b), and RGOSb (c).

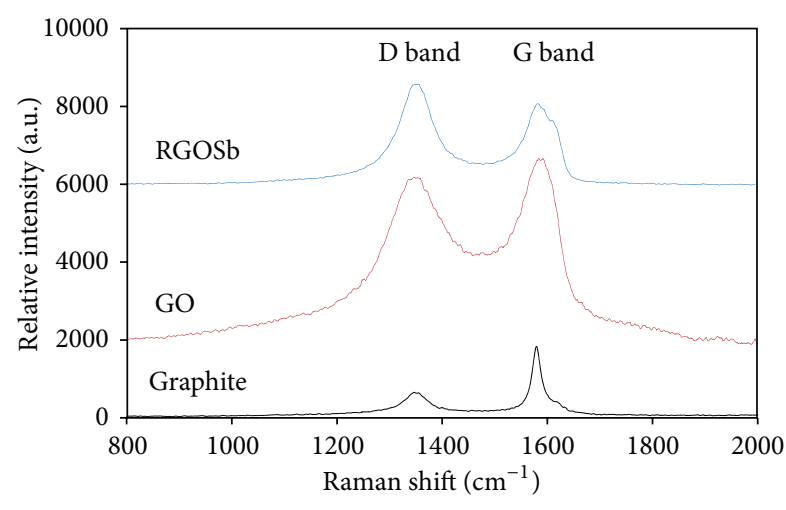

Figure 3: Raman spectra of graphite, GO, and RGOSb.

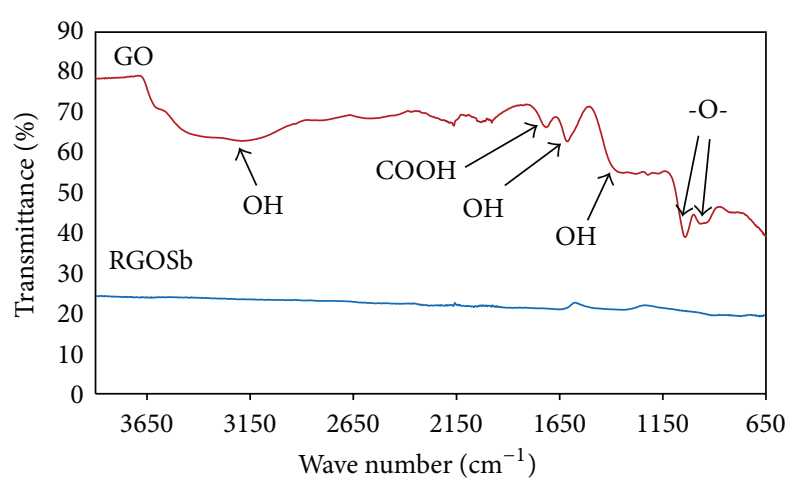

FIGURE 4: FTIR spectra of the GO and RGOSb.

After reduction of the composite in ethylene glycol, most of the signals disappeared, only one signal of the residual $\mathrm{OH}$ groups (higher magnification) located around $1,350 \mathrm{~cm}^{-1}$ was observed. This may indicate very efficient graphene oxide reduction in ethylene glycol; however, difficulties in removal of the $\mathrm{OH}$ groups from graphene oxide by chemical reduction were confirmed [31].

Electrodes were characterized in the two-electrode cell by the cyclic voltammetry, galvanostatic charge/discharge, and electrochemical impedance spectroscopy. The CV curves show the reversible charge/discharge characteristics of the composite electrode. Experiments were carried out at scan rate $5 \mathrm{mV} / \mathrm{s}, 20 \mathrm{mV} / \mathrm{s}$, and $500 \mathrm{mV} / \mathrm{s}$ in two potential windows from 0 to $1 \mathrm{~V}$ and from -0.5 to $+0.5 \mathrm{~V}$. The potential window $0-1 \mathrm{~V}$ is more often used in aqueous electrolyte supercapacitors experiments [32]; therefore, it was mainly used, while -0.5 to $+0.5 \mathrm{~V}$ window was used comparatively. Figure 5 compares the $\mathrm{CV}$ curves in the potential windows from 0 to $1 \mathrm{~V}$ and from -0.5 to $+0.5 \mathrm{~V}$ obtained for parent graphite (gray), graphite oxide (red), and reduced graphene oxideantimony species composite (blue) at the scan rate $20 \mathrm{mV} / \mathrm{s}$.

The well-developed supercapacitor has to satisfy two conditions, namely, operate in a possibly high current and have a box-like rectangular shape. Based on a Figure 5, it can be noticed that the most rectangular shape was recorded for the reduced graphene oxide-antimony species composite. It should be pointed out that better shape was obtained in -0.5 to $+0.5 \mathrm{~V}$. Although shape of the graphite and graphite oxide $\mathrm{CV}$ curves was acceptable, the average charging/discharging current was very low. The lowest average charging current and consequently the lowest specific capacitance was obtained for GO $0.00001 \mathrm{~A}$ and less than 1 F/g after 100 cycles. Amazingly high electrical resistivity cannot be balanced by the additional redox reactions of the oxygen-containing groups. Even for graphite, the average charging current was 50 times higher, that is, $0.0005 \mathrm{~A}$ with specific capacitance as high as $3 \mathrm{~F} / \mathrm{g}$. For RGOSb, the recorded charging current was $0.002 \mathrm{~A}$ and specific capacitance calculated from the CV curves was $13 \mathrm{~F} / \mathrm{g}$ after 100 cycles. Cyclability of RGOSb in comparison with graphite and graphite oxide was checked at scan rate $500 \mathrm{mV} / \mathrm{s}$ and 1000 cycles in a potential range $0-1 \mathrm{~V}$; the resulting CV curves were presented in Figure 6(a).

After 1000 cycles the specific capacitance of graphite dropped to $50 \%$ of the initial with a charging current of $0.0015 \mathrm{~A}$, while for GO difference between the first and the last step was quite small with the average charging current of $0.0004 \mathrm{~A}$. In RGOSb, once again the highest average charging current of $0.009 \mathrm{~A}$ and more rectangular shape were recorded; however, the specific capacitance dropped to $80 \%$ of the initial value. Additionally, Figure 6(b) presents shape difference of the CV curves recorded for RGOSb at $5 \mathrm{mV} / \mathrm{s}$ and 100 cycles in potential ranges $0-1 \mathrm{~V}$ and -0.5 to $+0.5 \mathrm{~V}$. This experiment showed that more ideal behavior was obtained for -0.5 to $+0.5 \mathrm{~V}$; however, higher current and 


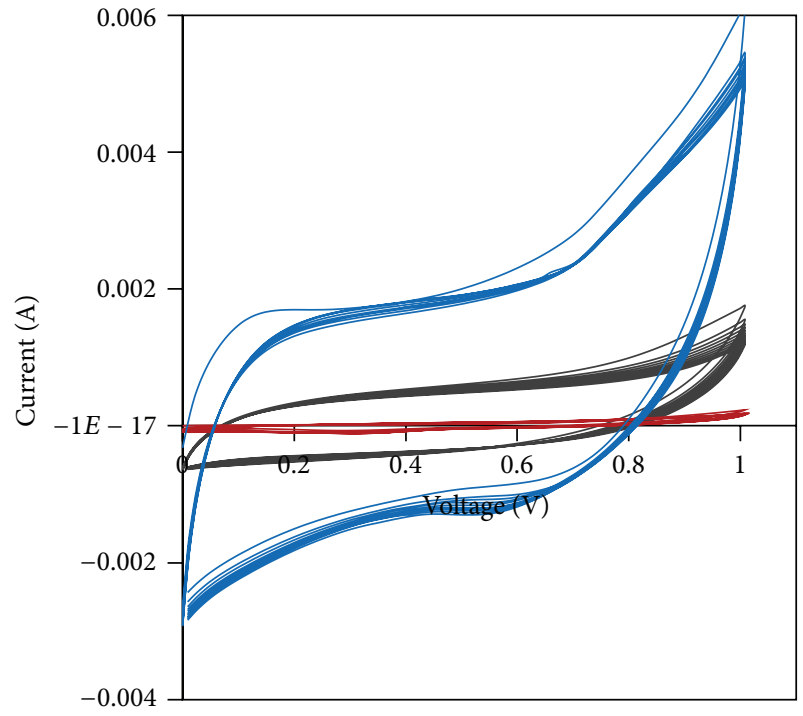

(a)

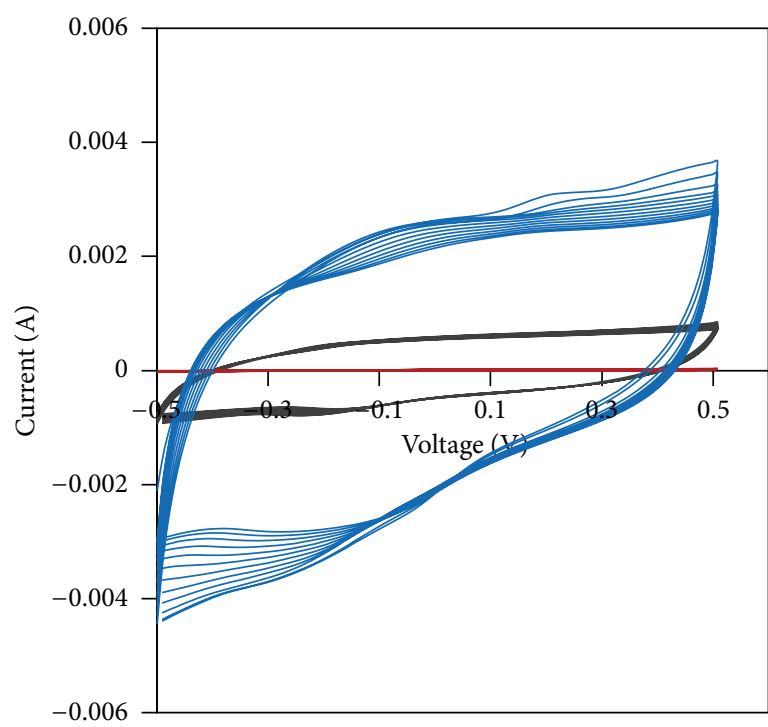

(b)

FIGURE 5: CV curves of graphite (gray), GO (red), and RGOSb composite (blue) registered in the two potential windows $0-1 \mathrm{~V}$ (a) and -0.5+ to $0.5 \mathrm{~V}$ (b) at the scan rate $20 \mathrm{mV} / \mathrm{s}$.

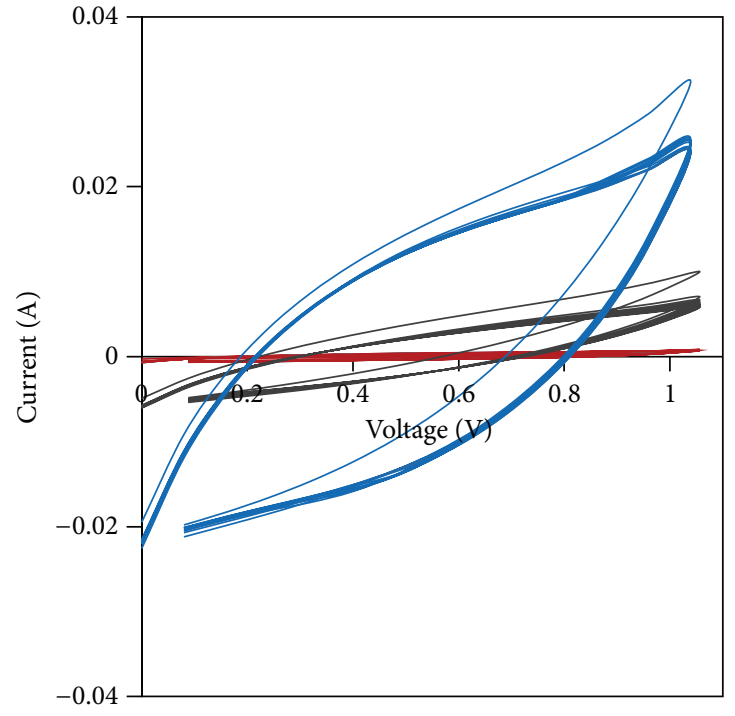

(a)

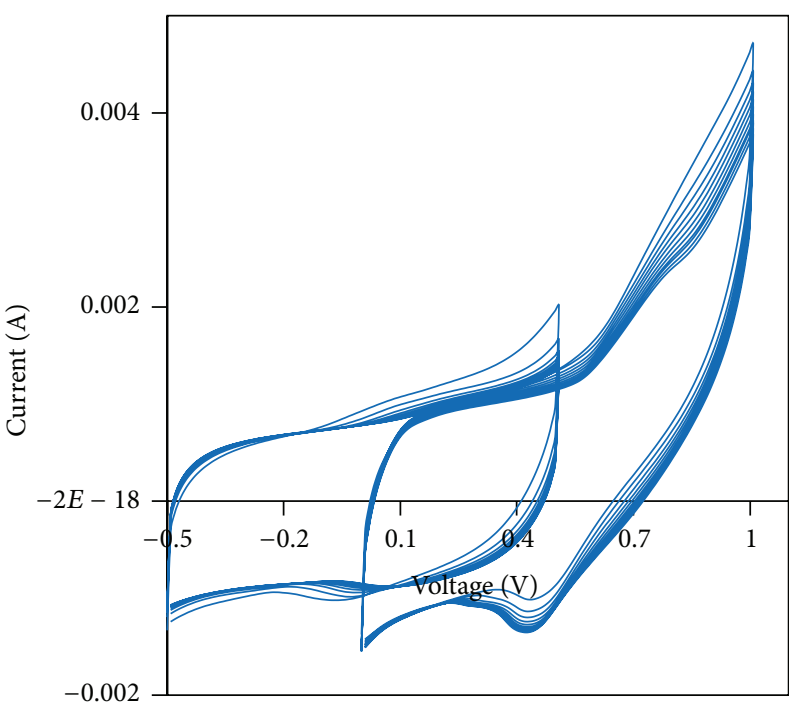

(b)

Figure 6: CV curves of graphite (gray), GO (red), and RGOSb (blue) at scan rate $500 \mathrm{mV} / \mathrm{s}$ and 1000 cycles (a) and comparison of CV curves recorded for RGOSb at $5 \mathrm{mV} / \mathrm{s}$ and 100 cycles in two potential ranges (b).

higher specific capacitance may be obtained for voltage range $0-1 \mathrm{~V}$.

These results show univocally that antimony species in oxide hydroxide or hydrated form is able to enhance the specific capacitance of graphite oxide many times. This is mainly attributed to the additional Faradaic reactions of the active antimony species with the electrolyte. Although it has been demonstrated in literature that the oxygen-containing functional groups of graphite oxide can enhance the total capacitance through Faradaic reactions and may improve the wettability of porous carbon with electrolytes [33], it was not observed here; however, the enhanced capacitance was obtained for GO modified with antimony species.

The galvanostatic charge/discharge is the most credible method to calculate the specific capacitance. It is used to show real capacitance value and charge/discharge characteristics 


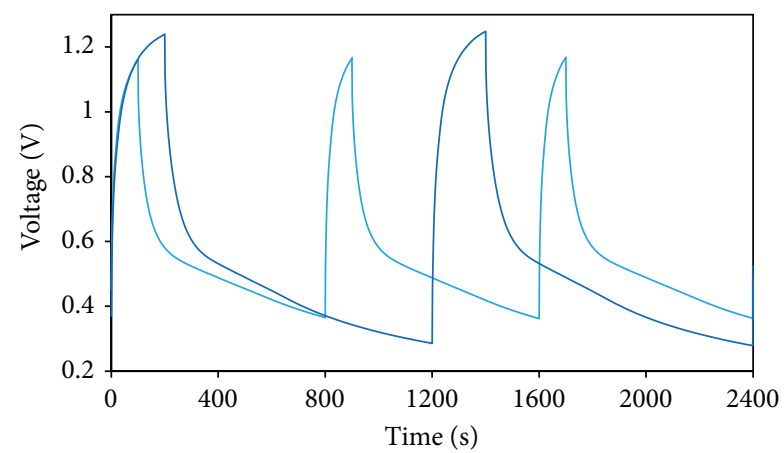

FIgURE 7: Galvanostatic charge/discharge curves of RGOSb at $0.004 \mathrm{~A}$ with discharge time $700 \mathrm{~s}$ (light blue) and $1000 \mathrm{~s}$ (dark blue).

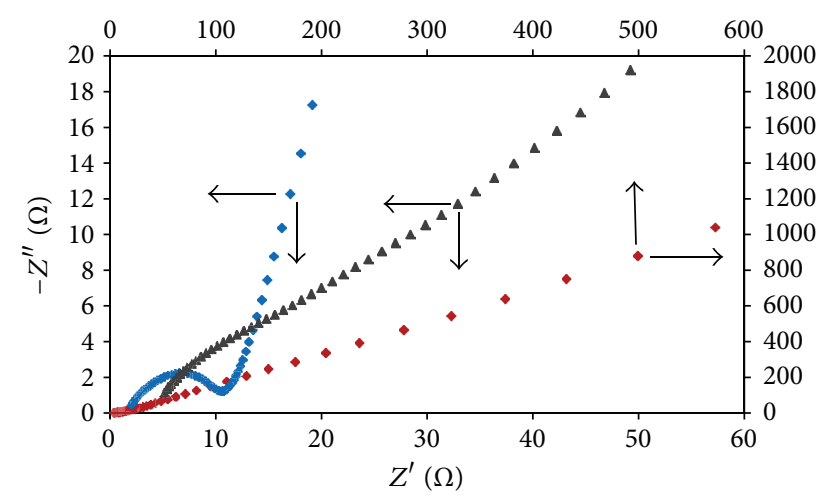

FIGURE 8: Nyquist plots of graphite (gray), GO (red), and RGOSb composite (blue) over the frequency range from $100 \mathrm{kHz}$ to $100 \mathrm{mHz}$.

of energy storing materials. Figure 7 shows the galvanostatic charge/discharge curves obtained for RGOSb at different charge and discharge times.

RGOSb was galvanostatically charged at $0.004 \mathrm{~A}$ for $100 \mathrm{~s}$ (light blue) and $200 \mathrm{~s}$ (dark blue) and discharged for $700 \mathrm{~s}$ and $1000 \mathrm{~s}$, respectively. The specific capacitance obtained from these measurements was $244 \mathrm{~F} / \mathrm{g}$ at shorter discharge time and $289 \mathrm{~F} / \mathrm{g}$ after $1000 \mathrm{~s}$. In both cases, quite unsymmetrical galvanostatic curves with quick charging and very long discharge time were obtained preceded by iR drop. The specific capacitance for RGOSb was much higher than that obtained for graphite and graphite oxide, $12 \mathrm{~F} / \mathrm{g}$ and $4 \mathrm{~F} / \mathrm{g}$, respectively.

Figure 8 shows the Nyquist plots of the impedance measured at an equilibrium open circuit potential $(0 \mathrm{~V})$ in the frequency range from $100 \mathrm{kHz}$ to $100 \mathrm{mHz}$. EIS plots present the quasireversible behavior of the reduced graphene oxideantimony species composite.

Generally, in the RGOSb composite, two regions can be distinguished including the semicircle corresponding to the Faradaic charge transfer resistance [34] and straight line in the low-frequency region indicating a pure capacitive behavior and representing the ion diffusion in the electrode structure. Steeper curve in the low-frequency region is attributed to the better Warburg diffusion. It is caused by an improved effective mass transfer from the electrolyte to the electrode interface in the composite. Neither in graphite nor in graphite oxide the semicircle was observed; however, graphite had steeper line in the low-frequency region. The maximum values of real resistance obtained for graphite, GO, and RGOSb were $100 \Omega, 880 \Omega$, and $19 \Omega$, respectively. Consequently, the specific capacitance obtained for RGOSb using the EIS method was about 75 times higher than that obtained for GO and about 10 times higher than that obtained for graphite.

\section{Conclusions}

In this work, the new reduced graphene oxide-antimony species composite has been prepared and characterized for supercapacitor electrodes. The polyol process was used to prepare dispersion of antimony active species in reduced graphene oxide. This method did not require thermal annealing of the active species into antimony oxides. It showed the enhanced specific capacitance, as high as $289 \mathrm{~F} / \mathrm{g}$, resulting from the pseudocapacitance and very good cyclability with respect to the parent graphite and graphite oxide.

\section{Conflict of Interests}

The authors declare that there is no conflict of interests regarding the publication of this paper.

\section{References}

[1] M. Filella, N. Belzile, and Y.-W. Chen, "Antimony in the environment: a review focused on natural waters I. Occurence," Earth-Science Reviews, vol. 57, no. 1-2, pp. 125-176, 2002.

[2] M. Kentner, M. Leinemann, K.-H. Schaller, D. Weltle, and G. Lehnert, "External and internal antimony exposure in starter battery production," International Archives of Occupational and Environmental Health, vol. 67, no. 2, pp. 119-123, 1995.

[3] Y. B. Kamenev, A. V. Kiselevich, E. I. Ostapenko, and Y. V. Skachkov, "Antimony-free alloys for unattended (sealed) lead batteries," Russian Journal of Applied Chemistry, vol. 75, no. 4, pp. 548-551, 2002.

[4] D. Pavlov, A. Dakhouche, and T. Rogachev, "Influence of antimony ions and $\mathrm{PbSO}_{4}$ content in the corrosion layer on the properties of the grid/active mass interface in positive lead-acid battery plates," Journal of Applied Electrochemistry, vol. 27, no. 6, pp. 720-730, 1997.

[5] M. Kosai, S. Yasukawa, S. Osumi, and M. Tsubota, "Effect of antimony on premature capacity loss of lead/acid batteries," Journal of Power Sources, vol. 67, no. 1-2, pp. 43-48, 1997.

[6] J. Yang, M. Winter, and J. O. Besenhard, "Small particle size multiphase Li-alloy anodes for lithium-ion-batteries," Solid State Ionics, vol. 90, no. 1-4, pp. 281-287, 1996.

[7] A. Trifonova, M. Wachtler, M. Winter, and J. O. Besenhard, "Sn$\mathrm{Sb}$ and $\mathrm{Sn}$-Bi alloys as anode materials for lithium-ion batteries," Ionics, vol. 8, no. 5-6, pp. 321-328, 2002.

[8] A. Dailly, P. Willmann, and D. Billaud, "Synthesis, characterization and electrochemical performances of new antimonycontaining graphite compounds used as anodes for lithium-ion batteries," Electrochimica Acta, vol. 48, no. 3, pp. 271-278, 2002.

[9] A. Dailly, R. Schneider, D. Billaud, Y. Fort, and P. Willmann, "New graphite-antimony composites as anodic materials for 
lithium-ion batteries. Preparation, characterisation and electrochemical performance," Electrochimica Acta, vol. 47, no. 26, pp. 4207-4212, 2002.

[10] A. Dailly, R. Schneider, D. Billaud, Y. Fort, and J. Ghanbaja, "Nanometric antimony powder synthesis by activated alkaline hydride reduction of antimony pentachloride," Journal of Nanoparticle Research, vol. 5, no. 3-4, pp. 389-393, 2003.

[11] S. Saadat, Y. Y. Tay, J. Zhu et al., “Template-free electrochemical deposition of interconnected $\mathrm{ZnSb}$ nanoflakes for Li-Ion battery anodes," Chemistry of Materials, vol. 23, no. 4, pp. 10321038, 2011.

[12] J. M. Mosby and A. L. Prieto, "Direct electrodeposition of $\mathrm{Cu}_{2} \mathrm{Sb}$ for lithium-ion battery anodes," Journal of the American Chemical Society, vol. 130, no. 32, pp. 10656-10661, 2008.

[13] F. D. Wu, M. Wu, and Y. Wang, "Antimony-doped tin oxide nanotubes for high capacity lithium storage," Electrochemistry Communications, vol. 13, no. 5, pp. 433-436, 2011.

[14] F. Montilla, E. Morallón, A. de Battisti, A. Benedetti, H. Yamashita, and J. L. Vázquez, "Preparation and characterization of antimony-doped tin dioxide electrodes. Part 2. XRD and EXAFS characterization," Journal of Physical Chemistry B, vol. 108, no. 16, pp. 5044-5050, 2004.

[15] Y. Wang, I. Djerdj, B. Smarsly, and M. Antonietti, "Antimonydoped $\mathrm{SnO}_{2}$ nanopowders with high crystallinity for lithiumion battery electrode," Chemistry of Materials, vol. 21, no. 14, pp. 3202-3209, 2009.

[16] S. Sladkevich, J. Gun, P. V. Prikhodchenko et al., "The formation of a peroxoantimonate thin film coating on graphene oxide (GO) and the influence of the GO on its transformation to antimony oxides and elemental antimony," Carbon, vol. 50, no. 15, pp. 5463-5471, 2012.

[17] R. A. Nistor, D. M. Newns, and G. J. Martyna, "The role of chemistry in graphene doping for carbon-based electronics," ACS Nano, vol. 5, no. 4, pp. 3096-3103, 2011.

[18] Y. Leng, W. Guo, S. Su, C. Yi, and L. Xing, "Removal of antimony(III) from aqueous solution by graphene as an adsorbent," Chemical Engineering Journal, vol. 211-212, pp. 406-411, 2012.

[19] M. Zhu, C. J. Weber, Y. Yang et al., "Chemical and electrochemical ageing of carbon materials used in supercapacitor electrodes," Carbon, vol. 46, no. 14, pp. 1829-1840, 2008.

[20] C. Lee, X. Wei, J. W. Kysar, and J. Hone, "Measurement of the elastic properties and intrinsic strength of monolayer graphene," Science, vol. 321, no. 5887, pp. 385-388, 2008.

[21] A. A. Balandin, S. Ghosh, W. Bao et al., "Superior thermal conductivity of single-layer graphene," Nano Letters, vol. 8, no. 3, pp. 902-907, 2008.

[22] X. Zhu, H. Dai, J. Hu, L. Ding, and L. Jiang, "Reduced graphene oxide-nickel oxide composite as high performance electrode materials for supercapacitors," Journal of Power Sources, vol. 203, pp. 243-249, 2012.

[23] L. Wang, D. Wang, J. Zhu, and X. Liang, "Preparation of $\mathrm{Co}_{3} \mathrm{O}_{4}$ nanoplate/graphene sheet composites and their synergistic electrochemical performance," Ionics, vol. 19, no. 2, pp. 215-220, 2013.

[24] Y. Wang, T. Brezesinski, M. Antonietti, and B. Smarsly, "Ordered mesoporous Sb-, Nb-, and Ta-doped $\mathrm{SnO}_{2}$ thin films with adjustable doping levels and high electrical conductivity," ACS Nano, vol. 3, no. 6, pp. 1373-1378, 2009.

[25] L. Staudenmaier, "Verfahren zur Darstellung der Graphitsaure," Berichte der Deutschen Chemischen Gesellschaft, vol. 31, no. 2, pp. 1481-1487, 1898.
[26] Z. Liu, J. Y. Lee, W. Chen, M. Han, and L. M. Gan, "Physical and electrochemical characterizations of microwave-assisted polyol preparation of carbon-supported PtRu nanoparticles," Langmuir, vol. 20, no. 1, pp. 181-187, 2004.

[27] H.-W. Ha, I. Y. Kim, S.-J. Hwang, and R. S. Ruoff, "Onepot synthesis of platinum nanoparticles embedded on reduced graphene oxide for oxygen reduction in methanol fuel cells," Electrochemical and Solid-State Letters, vol. 14, no. 7, pp. B70B73, 2011.

[28] L. A. Zemnukhova and A. E. Panasenko, "A novel composite material based on antimony(III) oxide," Journal of Solid State Chemistry, vol. 201, pp. 9-12, 2013.

[29] K. Oorts, E. Smolders, F. Degryse et al., "Solubility and toxicity of antimony trioxide $\left(\mathrm{Sb}_{2} \mathrm{O}_{3}\right)$ in soil," Environmental Science \& Technology, vol. 42, no. 12, pp. 4378-4383, 2008.

[30] M. Filella, N. Belzile, and Y.-W. Chen, "Antimony in the environment: a review focused on natural waters II. Relevant solution chemistry," Earth-Science Reviews, vol. 59, no. 1-4, pp. 265-285, 2002.

[31] S. Pei and H. M. Cheng, "The reduction of graphene oxide," Carbon, vol. 50, no. 9, pp. 3210-3228, 2012.

[32] M. D. Stoller and R. S. Ruoff, "Best practice methods for determining an electrode material's performance for ultracapacitors," Energy \& Environmental Science, vol. 3, no. 9, pp. 1294-1301, 2010.

[33] B. Xu, S. Yue, Z. Sui et al., "What is the choice for supercapacitors: graphene or graphene oxide?" Energy \& Environmental Science, vol. 4, no. 8, pp. 2826-2830, 2011.

[34] Y. Chen, X. Zhang, D. Zhang, P. Yu, and Y. Ma, "High performance supercapacitors based on reduced graphene oxide in aqueous and ionic liquid electrolytes," Carbon, vol. 49, no. 2, pp. 573-580, 2011. 

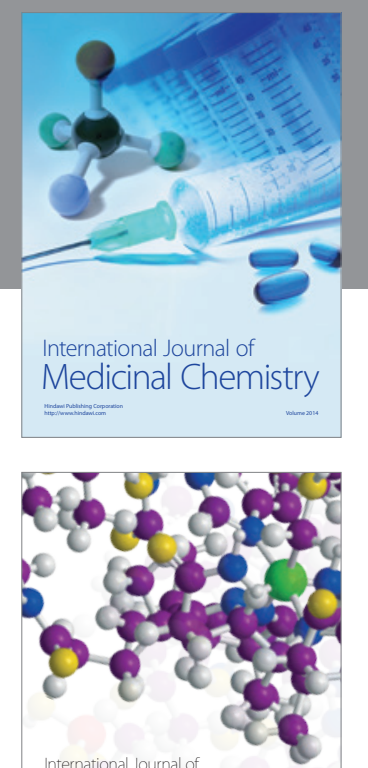

\section{Carbohydrate} Chemistry

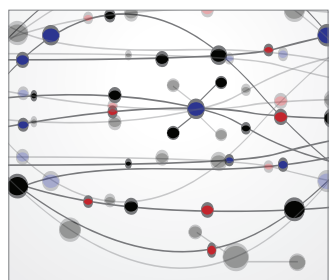

The Scientific World Journal
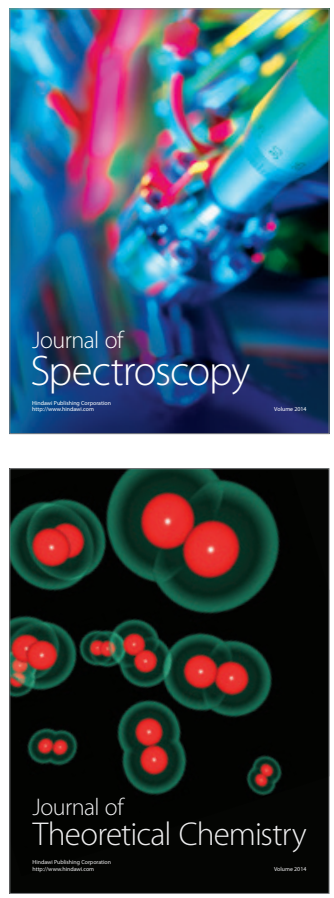
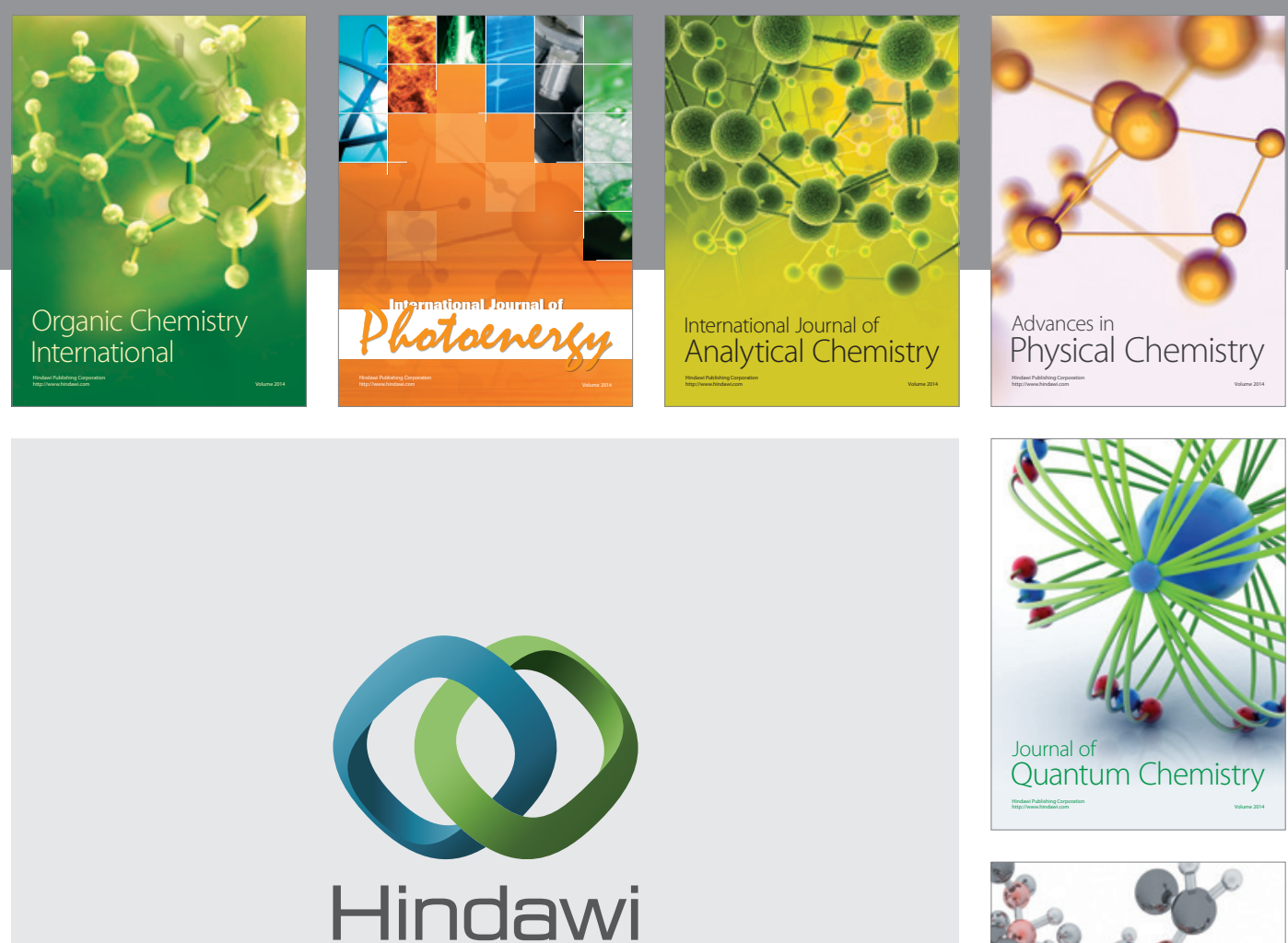

Submit your manuscripts at

http://www.hindawi.com

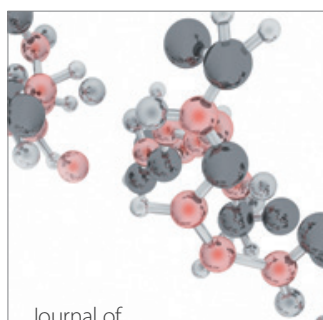

Analytical Methods

in Chemistry

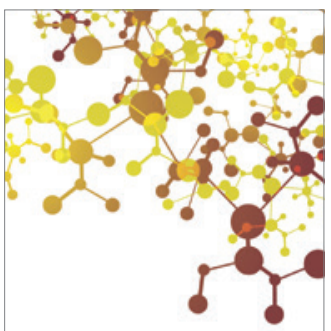

Journal of

Applied Chemistry

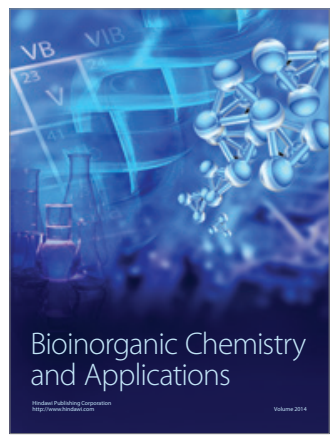

Inorganic Chemistry
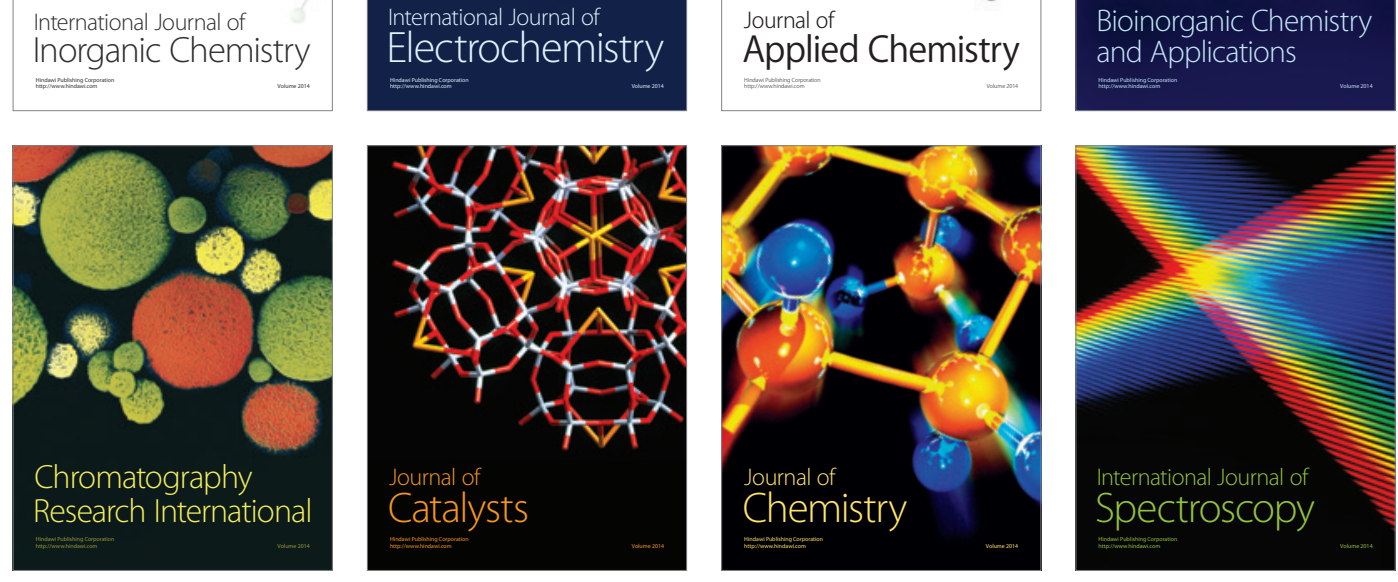